\title{
Parents' views of supermarket fun foods and the question of responsible marketing
}

Rebecca C. Den Hoed and Charlene Elliott

Department of Communication and Culture, University of Calgary, Calgary, Canada.

\begin{abstract}
Purpose - Despite their responsibility for mitigating the influence of commercial culture on children, parents' views of fun food marketing aimed at children remain largely unexplored. This article aims to probe parents' views of supermarket fun foods and the packaging used to promote them to children.

Design/methodology/approach - In total 60 in-depth interviews were conducted with parents from different educational backgrounds, living in three different Canadian cities. Interview responses were analyzed and coded thematically using an iterative process in keeping with grounded theory.
\end{abstract}

Findings - Parents generally discussed the promotion of supermarket fun foods to children as either an issue of the nutritional quality of foods promoted to children and/or in light of the communication quality of marketing aimed at children. Parents were also divided along education lines: parents with higher educational backgrounds were more likely to oppose fun foods and praise more pastoral ideals food production and consumption, while those with less education more often praised fun foods.

Research limitations/implications - These findings cannot be generalized to other parents or parents in other countries. The findings, however, suggest that a more nuanced consideration of differences within and across parents' views is warranted in debates about responsible marketing to children.

Originality/value - This article provides a qualitatively rich snapshot of the views of 60 Canadian parents regarding child-targeted food marketing, and raises important questions about how to incorporate parents' views into discussions about responsible marketing, rather than presuming they are all of one mindset.

Keywords Supermarket food, Fun food, Packaging, Marketing, Parents, Children (age groups), Food packaging, Canada

Paper type Research paper

The childhood obesity epidemic has sparked considerable interest in food marketing aimed at children. This interest is due, in part, to the questionable impact food marketing has had on children's health: it is a multi-billion dollar industry that influences children's food preferences and consumption (Livingstone and Helsper, 2004), and a problem arises because such marketing typically promotes high fat, sugar, and (HFSS foods) to children, despite evidence that these foods put children's health at risk (Institute of Medicine, 2006; Interagency Working Group on Food Marketed to Children, 2011; World Health Organization, 2010)[1]. Interest is also due to 
the potential positive impact food marketing could have on children's health. Presumably, more responsible food marketing could improve children's health. However, opinions vary about what counts as responsible marketing (e.g. Pettersson and Fjellstrom, 2006; Samson, 2005; Tucker, 2004; Nixon, 2004; Schwartz and Ustjanauskas, 2012).

Debates about responsible food marketing to children, however, tend to focus on TV advertising (Livingstone and Helsper, 2004), even though marketers increasingly use new media (e.g. advergames) to reach young consumers (Harris et al., 2010). Yet older media such as packaging is equally important. Packaging is, after all, a form of media which can significantly influence consumers’ food choices (Kelly et al., 2009; Silayoi and Speece, 2004; Page et al., 2008). Yet few policy debates or regulations target product packaging aimed at children in supermarkets (Berry and McMullen, 2008; Elliott, 2008a). Given that most food selection occurs within the supermarket (Tarasuk, 2010), it is important to consider supermarket foods, and their packaging, aimed at children (and their parents).

Currently, little is known about how parents view the issue of supermarket foods aimed at children. This study outlines Canadian parents’ views of child-targeted supermarket foods and packaging and highlights divides across and within parents' views. This study also considers what parents' views reveal about their underlying attitudes toward responsible marketing of supermarket foods to children, and how parents' views fit into broader debates about responsible food marketing and packaging aimed at children.

\section{Supermarket fun foods: a profile}

Before proceeding to the details of the study, it is important to clarify what is meant by childtargeted supermarket foods, or "fun foods." The term "fun foods" refers to foods marketed to children as “fun'” to eat or as “'eatertainment”' (Roberts, 2005; Elliott, 2010). Specific techniques used to market packaged supermarket foods in this way include using cartoon imagery, children's characters, celebrities, or movie/TV tie-ins on the package; including free gifts suitable for children in the package; using words like "kids" or "children" on the package[2] to identify it as just for kids; encouraging interactive play on the package or with the food itself; incorporating unusual sensory experiences in the product design or packaging (e.g. wild colours, flavours, shapes, textures, smells); and even printing children's characters directly 
on the food (Roberts, 2005; Fitzhugh and Lobstein, 2000; Hunter, 2002; Elliott, 2010; Mehta et al., 2012). Fun food treats food as something other than food: as an entertaining or comic plaything, symbolically opposed to the seriousness of adult food (De lulio, 2010; Elliott, 2010, 2011).

Fun foods can be found throughout the supermarket in every category of foods (Elliott, 2008b; Mehta et al., 2012). However, their nutritional profile tends to be poor (Harris et al., 2010). Up to 89 per cent of supermarket fun foods - and as many as 65 per cent of 'better for you' fun foods - qualify as HFSS foods (Elliott, 2008a, b, 2012a; Chapman et al., 2006; Mehta et al., 2012). In fact, poor nutritional quality has been linked to specific fun food marketing techniques, with spokes-characters appearing most often on unhealthy foods (Berry and McMullen, 2008; Hebden et al., 2011).

The persuasive effects of fun food packaging on children have also been documented, with fun packages creating brand awareness (McNeal and Ji, 2003) and spokes-character recognition (Hill and Tilley, 2002) in young consumers. Fun packaging also makes children more inclined to choose particular foods: foods in packages featuring a favourite colour (Marshall et al., 2006; Gollety and Guichard, 2011), a branded character (Wansink et al., 2012)[3], or a junk-food appearance (Pires and Agante, 2011). Fun packaging also inclines children to eat more (MusherEizenman et al., 2011) and to prefer the taste of food (Lapierre et al., 2011), even as “fun"' appeals override children's understandings of the food's nutritional merit (Lapierre et al., 2011)[4].

Children, however, are not the only ones influenced by fun marketing appeals. Fun food packaging equally affects parents' choices - indirectly, through "'pester power”' (e.g. Turner et al., 2006; Kelly et al., 2006) and also directly (Azad et al., 2012). Parents are influenced by nutrient claims on fun foods (Harris et al., 2011; Dixon et al., 2011) and use fun packaging to assess whether or not their children will eat the food (Gelperowic and Beharrell, 1994). The influence of nutrient claims on purchase decisions is problematic, though, given that many fun foods featuring nutrient/health claims can be of suspect nutritional quality (Elliott, 2012a; Harris et al., 2010).

\section{Supermarket fun foods: responsible marketing}


Given the impact of fun food packaging on both children and adults, scholars have begun to consider what (more) responsible fun food marketing might look like. On one hand, some scholars support the idea of using “fun” packaging to promote healthier foods to children by using fun product names (Musher-Eizenman et al., 2011), branded or third-party licensed characters (Harris et al., 2010; Wansink et al., 2012), or packages modelled on junk food (Pires and Agante, 2011). These tactics - which focus on marketing's capacity to "be an effective tool to encourage children to make more healthful choices" (Federal Trade Commission, 2011) - are considered effective for increasing children's interest in healthy foods and counter-balancing the prevalence of HFSS foods already on the market.

On the other hand, scholars warn that appeals to fun can interfere with children's abilities to assess the nutritional quality of foods (Elliott, 2012a; Lapierre et al., 2011) and contribute to over-eating.

Most scholars agree, however, that food packaging warrants more recognition as a marketing tool and more regulation overall (Berry and McMullen, 2008; Elliott, 2012b; Mehta et al., 2012; Page et al., 2008; Hebden et al., 2011; Chapman et al., 2006; Harris et al., 2010). Food packaging and supermarkets are rarely covered by guidelines promoting responsible marketing to children (Berry and McMullen, 2008; Elliott, 2008a). Industry advocates counter that regulation is unwarranted because packaging is primarily "of interest to parents who shop for their children" (CFBAI, 2011a, p. vi) and falls outside the purview of regulations protecting children from marketing. They also argue that marketers already promote healthier packaged foods to children (e.g. Millar, 2005), making regulatory interventions unnecessary.

\section{Supermarket fun foods: parents' views}

Missing from this debate, however, is the voice of parents. More specifically, absent are the many different voices of parents. One methodological pitfall of studying parental attitudes toward food marketing aimed at children is "the assumption that concerned parents share a common perspective on the nature of the children's advertising problem"' (Grossbart and Crosby, 1984, p. 80). Parents are rarely asked to speak about their perspectives on food marketing to children - a strange oversight given parents' primary responsibility for making food choices for (and with) their children. Parents “exert the greatest influence over their children’s 
preferences and diets”, (CFBAI, 2011b, p. 1); indeed, one study reports that " parents were fifteen times more important than advertising as an influence on children's eating', (Bolton, 1983, cited in Buckingham, 2011, p. 113). Given their central role, parents’ voices should be pivotal to any discussion of what responsible food marketing should look like.

While studies probing parents' views of child-targeted food marketing remain sparse, recent scholarship reflects an increasing interest in parents' views of child-targeted food marketing generally - although not of fun foods, per se. This research highlights parent concerns about the negative health impact of food marketing on children (Ip et al., 2007; Kelly et al., 2009). However, parents' perceptions of this health impact vary, with black and Hispanic parents and parents raising an overweight child perceiving more (negative) impacts than other parents (Harris et al., 2012). Parents' levels of concern also vary, with higher levels of concern about the health impact of child-targeted food marketing reported by nutritionally oriented parents (Grossbart and Crosby, 1984) and lower levels of concern reported by parents who feel confident in their ability to regulate their child's media use and food choices (Mehta et al., 2010). Research also highlights parent concerns about the marketing communication techniques used on children: concerns that food marketing is exploitative and exposes children to messages that focus more on high profile personalities than on food and that mislead consumers about the healthiness of foods (Ip et al., 2007; Hesketh et al., 2005; Pocock et al., 2010).

When it comes to supermarket foods and food packaging specifically, though, little is known about parents' views. Some parents are disgruntled with supermarket food marketing because supermarkets are the main point of sale and a key site of parent-child conflict (Mehta et al., 2012). Australian parents reserve their “'highest level of concern” for child-targeted food marketing encountered at the supermarket " including the placement of products at supermarket checkouts, packaging of food products designed to attract children and the use of premium offers” (Kelly et al. 2009, p. 3). Similarly, US parents rank in-store promotions and cartoon characters on packages second only to TV commercials in terms of their impact on children's eating habits (Harris et al., 2012). Given these findings, supermarket foods and food packaging warrant more attention in research examining parents’ views of child-targeted food marketing. 
This study asks parents what they think about supermarket fun foods, probing their views about the marketing used to promote these foods to children. Our findings show that parents' views, for the most part, align with calls for the promotion of healthier fun foods to children. However, these views are nuanced. There are divisions within the perspectives voiced that suggest certain challenges face marketers who seek "to improve the unhealthy food marketing environment that surrounds children and support parents in their efforts to raise healthy children’ (Harris et al., 2012, p. 6.).

\section{Methods}

A total of 60 in-depth interviews were conducted with parents recruited from three major urban centres in Canada. In-depth interviews were chosen to facilitate the gathering of qualitatively rich information (e.g. Ip et al., 2007) and to enrich existing survey-based research on this topic (Bakir and Vitell, 2010; Dens et al., 2007; Grossbart and Crosby, 1984; Kelly et al., 2009; Kelly et al., 2006; Spungin, 2004; Worsley and Scott, 2000).

After review/approval from the University Conjoint Faculties Research Ethics Board, 20 parents were recruited from each of Fredericton, NB, Ottawa, ON, and Calgary, AB. We recruited parents who were the primary shopper for the family (55 participants were women), and sought an equal mix of lower education and higher education backgrounds: i.e. in each location, 50 per cent of the parents participating had at most a high school diploma (lower education, or LE) and 50 per cent had a post-secondary degree or higher (higher education, or HE). Education levels were tracked because food preferences and tastes have much to do with educational background (see Bourdieu, 1984). The study was interested in probing whether parents with similar education backgrounds held similar views. Moreover, since the study recruited from three major cities across Canada, using income cutoffs would be extremely challenging (i.e. the same household income in Fredericton would allow for a very different standard of living compared to Calgary).

Participants were provided a definition of fun food and images of various fun foods found in the supermarket. These images included: two varieties of fun shaped chicken nuggets; nine different “'fun’' breakfast cereals; and nine different child-targeted fruit snacks. As part of the semistructured interview guide that directed the discussion, parents were asked what they thought 
about these foods - referred to as "fun foods"' by interviewers - and their creation/promotion. Parents' answers were audio-recorded and transcribed verbatim. Interview transcripts were analysed and coded thematically using an iterative process in keeping with grounded theory. Nvivo software facilitated the data analysis.

The interview questions selected for analysis were:

- What do you think of child-oriented fun foods?

- Do you agree with the idea of creating and promoting child-oriented fun foods?

Although qualitative research studies resist quantification, at certain points we have noted the number of parents who voiced particular themes, so as to reveal the dominant (or subordinate) nature of the themes under consideration.

\section{Results}

Themes emerging from interviews were divided into the two frameworks parents invoked to characterise and evaluate fun foods:

1. communication quality; or

2. nutritional quality.

A total of 13 parents characterised fun foods exclusively in terms of framework \#1: communication quality, condemning or praising appeals to "fun" based on the messages they communicated or how they communicated with consumers. A total of 22 parents characterised fun foods exclusively in terms of framework \#2: nutritional quality, praising nutritious fun foods or condemning HFSS fun foods. The most dominant approach, however, drew from both of these frameworks: 25 parents interviewed combined aspects of communication quality and nutritional quality in their discussion.

Framework 1: an issue of communication quality

A total of 38 parents characterised and evaluated fun foods in terms of how food messages were communicated to children, regardless of the foods involved[5]. Three parents made exclusively positive comments about fun food packaging; twenty-four made exclusively negative comments 
about it; and eleven had both good and bad things to say. Positive remarks were more common among LE parents, while exclusively negative remarks were more common among HE parents.

Positive remarks were categorised into two sub-themes: fun messages and helpful messages. Negative remarks were categorised into four sub-themes: selfish goals, vulnerable audiences, distracting messages, and deceptive messages.

Fun messages. A handful of (mostly LE) parents applauded fun food packaging for communicating to children that meals can be "fun" (Kristina LE) and "interesting”" (Deanne LE), and for making "kids happy" (Tony HE). One parent even framed appeals to "fun" as necessary to get young children to try new foods: "You have to have those fun shapes and colours to... get their interest' (Angela LE). Instead of raising concerns about child-targeted food marketing, these parents celebrated appeals to fun as messages promoting harmless, even necessary, child-oriented entertainment.

Helpful messages. Among parents who lauded fun food marketing, a few also praised it for communicating messages that were helpful to parents. They appreciated appeals to "fun"' designed to encourage " 'fussy" (Deanne LE) children to eat, which led to parental contentment: "If you can make anything fun for him that he's going to eat, I will be so happy" (Mary LE). A few parents also praised fun packaging for communicating product information that made parents “aware of... different varieties” (Kristina LE) of food their children might want or need. Selfish goals. Far more prevalent, were parents' criticisms of the kinds of communication fun foods prompted with consumers. Parents complained, for instance, that fun food packages were evidence of food companies' selfish communication goals. Parents described fun foods as little more than superficial "gimmicks"' (Catherine HE) designed to seize consumers' attention and entice them to buy more and pay more for products. Parents linked fun foods with corporate greed and a lack of care for consumers: "it is all about making money and food manufacturers not caring what they sell to people just as long as they make money’' (Dawn HE).

Similarly, parents complained about the cost of child-oriented edibles, describing them as "very expensive" (Heidi LE) and not "worth the price”' (Deanne LE). These parents felt higher prices were yoked to “pretty little packages" (Lori HE) and “'smaller portions” (Leanne LE) designed 
to trick parents out of their money. While some parents acknowledged "the business side of it" (Mark HE), they felt food companies were passing packaging costs onto consumers: “my thoughts on all of that packaging and all of that trying to make it fun is that they're spending too much money doing that they're not investing in their product’’ (Mark LE). These parents understood the drive for companies to make a profit, but characterised 'fun” packaging as evidence that companies were out to benefit themselves and could not be trusted as consumeroriented communicators.

Vulnerable audiences. Many parents also complained that fun food marketing targeted vulnerable audiences with their marketing messages. They expressed frustration that the food industry would exploit children and use them to manipulate parents. Younger children were singled out by parents as especially vulnerable - as "very susceptible” to food marketing (Sally HE) and likely to get “sucked in”' (Deanne LE) or be “swayed” (Anna HE). As one parent explained, children are too young “to make smarter decisions”, (Amanda HE) when faced with fun packaging: “'at least as adults we can recognise . . 'no I don’t actually want that hamburger', kids can’t do that they don't quite have that distinguished yet, they just see it and want it. So I think that's pretty bad for people to be preying on that'’ (Amanda HE). Other parents framed children as unable to control their emotional responses to " fun”, appeals and prone to “'break down”' (Jennifer LE) or “'beg”' (Cheryl LE) for products.

Parents also believed that adults were unfairly targeted and reported feeling "bombarded” (Mark HE), “manipulated”' (Deirdre LE), and “pressured”' (Saima HE) by the confluence of nagging children and confusing labels encountered at the supermarket. Parents resented, in particular, being pressured "through [their] kids”, (Saima). While one parent admitted this was not “anything illegal”' (Mark HE), he felt it was “ethically... wrong”' (Mark HE). These sentiments perhaps reflect the often intense pressures faced by parents at the supermarket, where children are ideally positioned to pressure parents to buy foods (Wilson and Wood, 2004).

HE parents also singled out defenseless parents as those lacking the time or knowledge to resist intense marketing pressures, including pressures from their own children (i.e. pester power): they described vulnerable parents as “other” parents (not themselves) who shop with their children because they “don't have a lot of time”' (Gabrielle HE) and who give in to food requests 
because they "don't have time with their children ... and want to keep the children happy" (Gabrielle HE). These "other” parents were also presumed to be more "easily swayed" (Catherine HE) by marketing because they were unaware of the range of foods available. They were pitied by HE parents for resorting to food choices that were "unfortunate” (Anna HE), but understandable.

Distracting messages. Parents did not just take issue with the selfish ethos of fun food marketers and the vulnerable audiences they target; parents also complained that fun food messaging distracts children from thinking about food as food, understanding its origins, production, and nourishing qualities. While it is arguably not the responsibility of marketers to focus children's attention on food as food, parents felt distracting children from thinking about food as food was an obstacle to their children developing an understanding what foods are, and which are good for them to eat (not just good to play with). HE parents, in particular, characterised fun food packaging as a ploy to entice children to prefer foods wrapped in pretty packages, without thinking about the food inside or about less-packaged alternatives.

On one hand, LE parents voiced concerns that fun food marketing distracted children from thinking about food as fuel, as something that feeds the body and that is "to be eaten, not played with”' (Angela LE). These parents highlighted the qualities of food that flashy packaging encourages children to overlook: "the child is not thinking about what's good for them and the nutritional value of the food. They're just thinking... 'Hey. This is way cool, because it's Transformers or it's Diego or Thomas"' (Karen LE).

On the other hand, HE parents voiced concerns that fun food packaging distracted children from understanding and appreciating the pastoral qualities of food. 'Pastoralism," here, refers to a tendency to value foods that embody pastoral contexts (e.g. organic, natural, whole foods) and the close and caring social relations these contexts entail[6]. Such pastoralism has been linked with the food ideals of American “yuppies” (Guthman, 2007) and prevailed among the HE parents interviewed. Specifically, HE parents lamented that fun food packaging prevented children from learning about and valuing food's origins in nature, agrarian and at-home food production, and the nourishment provided by natural foods and family meals. 
When it came to the origin of foods and food production, for instance, HE parents voiced concern that food packaging distracted children from understanding " where the food comes from”' and 'the people”' who produce it (Kelly HE). One parent believed pre-packaged foods distracted her child from thinking about food origins, food preparation, and food's role "in the global economy and... ecology” (Yvonne HE). She wanted her child to develop " a healthy interest in food”' before being exposed to marketing: “'I would prefer, that they get interested in the food and preparing it themselves and moving on. To get that better, down pat, better before they started being marketed food directly because it doesn't come like that. It's like we think pork chops come on Styrofoam. This removes them one more step from food prep and our origin’' (Yvonne HE).

HE parents also voiced concerns that fun food marketing distracted children from thinking about the nourishment provided by less-contrived or less-packaged foods and mealtimes. These parents blamed appeals to "fun', for distracting children from understanding the deep social nourishment provided by authentic food-inspired conviviality, as opposed to the contrived “fun”, of pre-packaged "'eatertainment”, (Elliott, 2010). For these parents, “the atmosphere around the table [should] be fun, not the... food itself”' (Gabrielle HE): “You know, it would be better if families sat at the table and had a fun conversation rather than just being absorbed by the shape of ... whatever it is they're eating'’ (Anna HE). Overall, they objected to marketing that focused children's attention on pre-packaged foods and experiences, at the expense of encouraging kids to think about food beyond the fun packaging.

Deceptive messages. A few parents also expressed concern that fun food packaging communicated deceitful messages, especially regarding the overall healthiness of packaged foods. Packages made it harder for parents to judge “'what is nutritious and what isn't”' (Dawn HE), and confused parents with “disingenuous” (Sarah LE) health claims true only " on the surface”' (Gabrielle HE). A few parents stopped short of accusing marketers of "false advertising”, (Mary LE), and expressed hope that “what [marketers] say about the food is true”, (Joan LE), signaling that this was not assured.

This pattern in parents' attitudes reveals a framework for understanding and evaluating fun foods rooted primarily in the quality of communications directed at consumers. Fun foods were praised 
if they communicated helpful messages to consumer, and blamed if they showed evidence of selfish communication goals, targeting vulnerable audiences, or communicating misleading or distracting messages to consumers - irrespective of the foods involved. This highlights just how thoroughly parents frame fun foods as an issue of communication - or miscommunication.

Framework 2: an issue of nutritional quality

However, parents (also) invoked a second, distinct framework for understanding and evaluating fun foods that foregrounded the nutritional quality of foods promoted to children.

A total of 47 parents characterised and evaluated fun foods in terms of the nutritional quality of foods promoted to children, mostly condemning food packages containing/promoting HFSS foods to children or celebrating food packages containing/promoting healthier foods[7]. One parent believed all fun foods were nutritious and therefore supported all fun food marketing. Thirteen affirmed that fun foods were never healthy and opposed the promotion of junk to children, or tolerated their promotion only as treats. Thirty-three parents believed fun foods could be healthy, depending on the product, and sanctioned the promotion of healthier products to children.

Characterisations of poorly nutritious fun foods were categorised into the sub-themes of unhealthy and harmful packaging. Characterisations of 'better-for-you”' fun foods were categorised into the sub-themes of exceptional foods and expedient packaging.

Unhealthy foods and harmful packaging. Parents who highlighted the poor quality of fun foods described them as “totally unhealthy” (Carole LE), “terrible” (Sharon HE), “junk”' (Kelly HE), “sugar-filled”' (Cheryl LE), or “artificial”" (Karen LE). A few parents considered them treats not to be counted as " part of [a child's] diet”' (Shannon HE). Others described them in terms of their negative health consequences, as “detrimental to" (Chris HE) children's health, and as the cause of obesity, cancer, or poor health later in life: “In the end, they won't find their bones healthy or their eyesight, they won't find the health that they'll want in their later years"' (Fay HE).

Once parents established that fun foods were junk, they expressed concern that food packaging was used to make unhealthy foods look “"cool”' (Michelle HE). HE parents were especially 
vehement in their condemnations, arguing that such packaging "pushe[d]" (Lori HE) children into bad food choices by getting them "hooked” (Chris HE) on "addictive”' (Saima HE) foods. LE parents, in contrast, condemned fun food packaging for normalizing unhealthy treats as everyday kids’ foods: “'they give a bad representation of what kids' food is to kids”' (Amanda LE); and "there's always the impression that somebody else is eating it all the time"' (Brian LE). These critiques, however, were always yoked to concerns about foods of poor nutritional quality. The packaging was a problem only if it was used to entice children to consume garbage foods: “'The marketing itself isn’t evil. It's what they are marketing that concerns me” Sharon (HE). Exceptional foods and expedient packaging. More surprising, however, was the number of parents who went out of their way to point out that not all fun foods were “junk”, (Heather LE) or “crap”' (Kelly HE). While many parents implied healthy fun foods existed, several insisted that some were “okay"' (Michelle HE), that they seemed to be getting healthier, and in some cases were "'not much different than regular food”' (Lilian LE). However, parents' confidence about so called “'better-for-you”, products was almost always qualified[8]. Healthier options were framed as exceptions or outliers: only "some” or "a few”' were acceptable. Indeed, for some, the existence of healthier fun foods was more wish than reality: "I wish they could do that more often with things that are real food”' (Sharon HE); “I wish they made them completely sugar-free’’ (Sonja HE).

However, once these parents stipulated that the foods in question were (or might be) healthy, their views of fun food packaging were remarkably positive. In place of concerns about marketing communications, they voiced approval for promoting healthier foods to children: “if it gets the kids to eat nutrients that are good for their growing bodies and brains... then that's okay” (Mark HE); “I don’t think there is any harm if a child is looking for an elephant in his soup.... as long as the nutritional quality is there’’ (Tannis HE).

Some parents even advocated for more “fun’” marketing for healthier foods. One parent thought it would be "'wonderful"' (Sharon HE) if companies used "the exact same marketing techniques [for junk food]... but with real food and healthy food”’ (Sharon HE). Another parent suggested using TV/movie tie-ins to get kids to try vegetables: "You know, I mean, that's kind of a nobrainer... If you somehow had Hannah Montana, Transformer Brussel sprouts, I think you'd have 
a shot of at least having the kids try it somehow"' (Mark HE). Some parents thus voiced support for what McDermott et al. (2006, p. 534) call " the delightful prospect of... five-year-olds

throwing tantrums... because they want Superman broccoli rather than Teletubbies carrots"' - not because they want junk foods rather than healthy foods.

Moreover, these parents valued healthy fun foods as a way to get fussy kids " to stay at the table long enough to actually eat what they should eat'” (Tannis HE). Fun foods could lessen conflict of mealtimes - although praise was always contingent on the food's positive nutritional value. As one parent explained, “I have a picky eater, so the fun foods are nice as long as they're eating them. The kids are happy. My husband and I will be happy because we don't have to argue with them or force them to eat or anything like that, but they do have to have some sort of nutritional value”' (Ligia LE).

This pattern in parents' attitudes suggests a framework for understanding and evaluating food marketing wherein nutritional quality is key and "fun" packaging is only a neutral delivery mechanism for food. If the food is healthier, the delivery mechanism is praised; if the food is junk, the delivery mechanism is blamed. What really counts for parents in this framework is nutritional quality. This stands in stark contrast to the (earlier described) framework wherein fun food packaging per se was praised or blamed for how it communicates with - addresses and works on - consumers, instead of the kinds of food it delivers to them.

\section{Alternating between frameworks}

While more than half of the parents adopted one of the above frameworks, 25 parents alternated between the two. These parents were not necessarily conflicted about how best to characterise and evaluate fun foods. For instance, one parent shifted between the two frameworks to praise fun food packaging as a helpful shopping tool, and to praise the positive nutritional quality of fun foods. On the flip-side, seven (mostly HE) parents alternated between the two frameworks to critique both what foods were marketed to children and how they were promoted.

Notably, though, 16 parents alternated between the two frameworks to complain about problematic communication tactics used on children (and parents) and to sanction the promotion of healthier fun foods to children - using the same (problematic) communication tactics. These 
parents, most of whom were from an LE background[9], voiced concerns about disrespectful, deceitful, or distracting packaging, yet were willing to defer these concerns if the nutritional quality of the food could be guaranteed.

For instance, one parent complained that packaging featuring TV tie-ins took advantage of children: "They use their favourite characters... [e.g. Sponge Bob, Blues Clues]. Because children can't make those kind of choices, they're too young to understand what's good for them and what's not. I feel that they take advantage of that and put their favourite character on the box’’ (Saima HE). However, later in the same interview she endorsed using fun packaging on food “'as long as they're promoting [children's] health, as long as they're nutritious, they're not going to make them obese, they’re not going to hurt their health’’ (Saima HE).

While most in this group did not voice this as a compromise, two parents conceded that promoting healthier foods to children was “'Machiavellian”' (Mark HE), yet necessary because some parents need to buy packaged kids' food ' because their lifestyle is so busy”' (Gabrielle $\mathrm{HE})$.

\section{Discussion and implications}

At first glance it appears that a majority of the parents interviewed for this study frame their views of supermarket fun foods as an issue of nutrition. These parents praised the idea of promoting nutritious foods to children using a range of “fun"' appeals, including the use of popular children's characters, cartoons, and movie/TV tie-ins on packages. These views echo scholars who call for more nutritious fun foods promoted to children. For these parents, more responsible marketing involves more nutritious foods inside “fun”' packages, rather than any changes to food packaging, per se.

However, viewing the results from another angle reveals that nearly two thirds of the parents interviewed frame fun foods as a communication issue and a communication problem. Key for these parents is the idea that certain kinds of communication, not just nutritionally poor foods, harm children. While some of these parents appear willing to defer their concerns about problematic marketing communication to support the promotion of healthier fun foods to kids, it would be misleading to read their support for healthier fun foods as absolute. Rather, their 
concerns about communication remain unaddressed by calls for more healthy fun foods and their willingness to shelve these concerns warrants further study[10].

Parents are concerned about two communication problems in particular. Parents object to communications that position consumers (especially children) as powerless: that prioritise profits over consumer welfare, prey on vulnerable consumers, and undermine consumers via misleading messages. While parents do not characterise these tactics as a direct threat to children's health, they criticise them for being exploitative and undermining children's health when the foods promoted are unhealthy (which most fun foods are). More responsible marketing for these parents involves communications wherein companies demonstrate more care for child health, target adults (not children), and provide enough information on food packages to enable parents to easily discern the overall healthiness of packaged foods.

Parents also object to communications that distract children from thinking about food as food. Key for these parents is the idea that "fun' packages prevent children from thinking beyond the package to consider the food inside and its health impact. These complaints echo scholars' warnings that appeals to “fun'” on food packages interfere with children's abilities to assess the healthiness of foods and encourage children to develop problematic relationships with food (Lapierre et al., 2011; Elliott, 2012a, b). However, some parents characterise “'health' more broadly, as covering physical, social, and ecological health (not just nutrition). More responsible marketing for these parents involves food packaging that does not discourage children from thinking about food as food or prevent children from developing food/health literacy[11].

While current scholarship suggests a degree of homogeneity in parents' views - namely, that parents are concerned about child-targeted food marketing and their views vary mainly in how they quantify the (negative) impact of marketing and their levels of concern - the present study suggests that parents' views are more heterogeneous. Notably, parents interviewed for this study invoke two conceptual frameworks for making sense of supermarket fun foods. These frameworks offer parents different - and in some respects incompatible - logics with which to shape and express their views. One encourages parents to think of the quality of communications used to promote fun foods as good or bad for children; the other encourages parents to view the nutritional quality of foods as harmful or beneficial for children. Interestingly, the latter 
framework emerges as dominant in the present study. Not only do most parents invoke the latter framework, but those who invoke the former tend to speak from the margins: decrying (or resigning themselves to) the current commercial reality characterised by ubiquitous childoriented food marketing. Many parents, however, simply struggle within or shift between the two frameworks, as if neither entirely harmonizes with their individual views.

Drawing attention to these two frameworks - their differences, their points of irreconcilability, their role as sites of struggle for parents - reminds us that neither can be invoked as representative of "the voice of parents." At best, we might conclude, that some parents believe fun food marketing communications is problematic, some parents support the marketing of healthier fun foods to children, and some believe/support both. These are certainly the most obvious conclusions to be drawn. However, in many ways, these conclusions gloss over the need to acknowledge divisions within and across parents' voices. Parents' views are diverse and conflicted. Attending to these differences reveals that parents' voices cannot be easily combined to make it seem like they agree or share concerns. Rather, careful qualitative analysis of parents' voices reveals that they are aligning their individual voices with different ways of speaking and thinking about the issue.

Notably, such different ways of thinking/speaking about the issue are also manifest in differences in parents' views along education lines. Specifically, a small number of HE parents, dismayed by the commercialisation and commodification of food, oppose fun foods in tones more vehement, more unyielding, and more fueled by pastoral idealism than evidenced in any of their LE counterparts. These HE parents champion pastoral alternatives (local, organic, and fresh foods; home-made foods; traditional family meals; farmers' markets), compare fun foods to addictive drugs, condemn supermarkets as hazards, and seek responsible food promotion elsewhere. They also single out "other” parents less able to defend themselves against intense marketing, thereby implying their own superiority and privilege as parents in the process. This tone is striking and remarkably - nowhere heard among LE parents, who tend more towards (provisional) praise and tolerance of fun foods in their interview responses.

On one level, this divide along education lines confirms and extends scholarship that shows parental concerns about child-targeted food marketing vary depending on levels of nutritional 
concern and parenting confidence (Mehta et al., 2010; Grossbart and Crosby, 1984), and shows their levels of concern also vary with educational background: more HE parents condemn supermarket fun foods, while more LE parents praise or tolerate them[12]. On another level, though, this divide highlights that parents' views vary in more than just intensity, despite the literature’s current focus on levels of concern. Parents' views vary depending on the ideological/conceptual framework(s) parents use to make sense of (and respond to) the issue at hand. Specifically, our analysis shows that some HE parents draw on pastoral idealism to make sense of the issue, and that this ideology shapes their views and concerns about fun food marketing.

Overall, parents’ views of supermarket fun foods are shaped by different ways of understanding and evaluating the issue. This is manifest in the two frameworks parents use to frame the issue of supermarket fun foods (i.e. as an issue of nutritional quality or an issue of communication quality) and the pastoral idealism voiced by some HE parents. Such differences in how parents make sense of and evaluate foods and food marketing - and not just how they quantify the impact of marketing on children or quantify their concerns - warrant closer examination in research into parents' views of child-targeted food marketing and the question of responsible marketing.

\section{Notes}

1. There is no evidence that food marketing causes childhood obesity. Rather, it is considered one of many factors that contribute to childhood obesity, and "food promotion must be understood within the larger web of causality underlying children's food choice, health and obesity', (Livingstone and Helsper, 2004).

2. Mehta et al. (2012) also argue that images of children (not just child-focused wording) can designate a "for kids" food product.

3. This effect applied only to healthy food; it did not carry over to an unhealthy food. That is, children were just as likely to choose a cookie featuring an Elmo icon as a cookie without the icon (Wansink et al., 2012).

4. This finding is echoed in Pires and Agante's (2011) study of the effects of ' fun'” apple slice packaging. The appeals to fun diminished children's perceptions of the food's healthiness, although it was "sill perceived as healthy” (p. 167).

5. A total of 13 parents characterized fun foods exclusively as a communication quality issue, while 25 characterized it as both a communication and nutritional quality issue. 
6. Scrinis (2008) contrasts pastoralism to nutritionism. While he does not use the term " "pastoralism"' in his discussion, the term captures the food qualities and food values that Scrinis describes.

7. A total of 22 parents characterized fun foods exclusively as a nutritional quality issue, while 25 characterized it as both an issue of nutritional and communication quality.

8. Only one parent insisted without qualification.

9. Not all of the parents who alternated between the two frameworks in this way were from an LE background: of the sixteen parents, five were HE parents and eleven were LE parents.

10. Similar contradictory views are voiced by parents in Ip et al.'s (2007) study, which finds parents divided about televised food ads aimed at children. Ip et al.’s use of focus groups, however, leaves open the possibility that these contradictory views result from parents negotiating compromises during focus group discussions. The present study's use of oneon-one interviews, in contrast, suggests that these contradictory views result from individual parents struggling (internally) with competing points of view. Moreover, the present study sheds light on how parents conflicted about these views reconcile them: by shelving concerns about marketing communications to support the marketing of "betterfor-you' foods to children. There is no evidence that parents' concerns about communications are diminished by this move. Rather, they appear deferred. The specific psycho-social mechanisms underlying this deferral would be a fruitful focus for future research.

11. While it's arguably not the responsibility of food marketers to teach children about such things as food origins and food traditions, neither should fun packaging appeals undermine broader social efforts to do so.

12. The study suggests a focus on parental concern can also be misleading: some parents went out of their way to praise fun foods, indicating that the term "concern' might not adequately capture or reflect their views.

\section{References}

Azad, N., Rafiee, M. and Hamdavipour, L. (2012), “'The role of children’s food packaging characteristics on parent's purchasing decisions', Management Science Letters, Vol. 2 No. 3, pp. 827-832.

Bakir, A. and Vitell, S.J. (2010), “The ethics of food advertising targeted toward children: parental viewpoint', Journal of Business Ethics, Vol. 91 No. 2, pp. 299-311, doi: 10.1007/s10551-009-0084-2.

Berry, B. and McMullen, T. (2008), "Visual communication to children in the supermarket context: health protective or exploitative?' , Agriculture and Human Values, Vol. 25 No. 3, pp. 333-348, doi: 10.1007/s10460-007-9110-0. 
Bourdieu, P. (1984), Distinction: A Social Critique of the Judgement of Taste, Routledge \& Kegan Paul Ltd, New York, NY, (R. Nice, Trans.).

Buckingham, D. (2011), The Material Child: Growing up in Consumer Culture, Polity, Cambridge.

Chapman, K., Nicholas, P., Banovic, D. and Supramaniam, R. (2006), “The extent and nature of food promotion directed to children in Australian supermarkets", Health Promotion International, Vol. 21 No. 4, pp. 331-339, doi: 10.1093/heapro/dal028.

Children's Food and Beverage Advertising Initiative (CFBAI) (2011a), “Re: Interagency Working Group on Food Marketing to Children: FTC Project No. P094513"', General comments and comments on the proposed nutrition principles and marketing definitions"' available at: http://nwnc.bbb.org/storage/0/Shared\%20Documents/CFBAI\%20IWG\%20Comment\%207-142011.pdf (accessed December 12, 2012).

Children's Food and Beverage Advertising Initiative (CFBAI) (2011b) |, “The U.S. children’s food and beverage advertising initiative fact sheet', available at: www.bbb.org/us/storage/0/Shared\%20Documents/ChildrensFoodBeverageFactssingle\%20v2.pdf (accessed October 2012).

De lulio, S. (2010), “The construction of fun in food advertisements targeting children”, Young Consumers, Vol. 11 No. 2, pp. 96-107, doi: 10.1108/17473611011065782.

Dens, N., De Pelsmacker, P. and Eagle, L. (2007), "Parental attitudes towards advertising to children and restrictive mediation of children's television viewing in Belgium”, Young Consumers, Vol. 8 No. 1, pp. 7-18, doi: 10.1108/17473610710733730.

Dixon, H., Scully, M., Wakefield, M., Kelly, B., Chapman, K. and Donovan, R. (2011), "Parent's responses to nutrient claims and sports celebrity endorsements on energy-dense and nutrient-poor foods: an experimental study”, Public Health Nutrition, Vol. 14 No. 6, pp. 10711079, doi: 10.1017/S1368980010003691.

Elliott, C. (2008a), “Taste rules: food marketing, food law, and childhood obesity in Canada”, Cuizine: The Journal of Canadian Food Cultures, Vol. 1 No. 1.

Elliott, C. (2008b), "'Marketing fun foods: a profile and analysis of supermarket food messages targeted to children”, Canadian Public Policy, Vol. 34 No. 2, pp. 259-273.

Elliott, C. (2008c), “Assessing 'fun foods': nutritional content and analysis of supermarket foods targeted at children”, Obesity Reviews, Vol. 9 No. 4, pp. 368-377, doi: 10.111/j.1467789X.2007.00418.x.

Elliott, C. (2010), “Eatertainment and the (re)classification of children's foods”, Food, Culture \& Society, Vol. 13 No. 4, pp. 539-553. 
Elliott, C. (2011), “'It’s junk food and chicken nuggets': children's perspectives on 'kids' food' and the question of food classification', Journal of Consumer Behaviour, Vol. 10 No. 3, pp. 133-140, doi: 10.1002/cb.360.

Elliott, C. (2012a), “Packaging health: examining 'better-for-you' foods targeted at children”, Canadian Public Policy, Vol. 38 No. 2, pp. 265-281, doi: 10.1353/cpp.2012.0010.

Elliott, C. (2012b), "Packaging fun: analyzing supermarket food messages targeted at children”, Canadian Journal of Communication, Vol. 37 No. 2, pp. 303-318.

Federal Trade Commission (2011), "Prepared statement of the Federal Trade Commission on the Interagency Working Group on Food Marketed to Children”, available at: www.ftc.gov/os/testimony/111012foodmarketing.pdf (accessed October 11, 2012).

Fitzhugh, K. and Lobstein, R. (2000), Children's Food Examined: An Analysis of 358 Products Targeted at Children, The Food Commission, London.

Gelperowic, R. and Beharrell, B. (1994), "'Healthy food products for children: packaging and mothers’ purchase decisions”, British Food Journal, Vol. 96 No. 11, pp. 4-8, doi: 10.1108/00070709410074623.

Gollety, M. and Guichard, N. (2011), "The dilemma of flavor and color in the choice of packaging by children”, Young Consumers, Vol. 12 No. 1, pp. 82-90, doi: 10.1108/17473611111114803.

Grossbart, S.L. and Crosby, L.A. (1984), 'Understanding the bases of parental concern and reaction to children's food advertising”, Journal of Marketing, Vol. 48 No. 3, pp. 79-92.

Guthman, J. (2007), "From the ground up: California organics and the making of 'yuppie chow"', in Maye, D., Holloway, L. and Kneafsey, M. (Eds), Alternative Food Geographies: Representation and Practice, Elsevier, Amsterdam, pp. 241-254.

Harris, J., Schwartz, M. and Brownell, K.D. (2010), “'Marketing foods to children and adolescents: licensed characters and other promotions on packaged foods in the supermarket", Public Health Nutrition, Vol. 13 No. 3, pp. 409-417, doi: 10.1017/S1368980009991339.

Harris, J., Thompson, J.M., Schwartz, M.B. and Brownell, K.D. (2011), “Nutrition-related claims on children's cereal: what do they mean to parents and do they influence willingness to buy?’, Public Health Nutrition, Vol. 14 No. 12, pp. 2207-2212, doi: 10.1017/S1368980011001741.

Harris, J.L., Milici, F.F., Sarda, V. and Schwartz, M.B. (2012), “Food marketing to children and adolescents: what do parents think?', available at:

www.yaleruddcenter.org/resources/upload/docs/what/reports/Rudd_Report_Parents_Survey_Foo d_Marketing_2012.pdf (accessed December 10, 2012). 
Hebden, L., King, L., Kelly, B., Chapman, K. and Innes-Hughes, C. (2011), “A menagerie of promotional characters: promoting food to children through food packaging”, Journal of Nutrition Education and Behavior, Vol. 43 No. 5, pp. 349-355, doi: 10.1016/j.jneb.2010.11.00.

Hesketh, K., Waters, E., Green, J., Salmon, L. and Williams, J. (2005), “'Healthy eating, activity and obesity prevention: a qualitative study of parent and child perceptions in Australia", Health Promotion International, Vol. 20 No. 1, pp. 19-26, doi: 10.1093/heapro/dah503.

Hill, H. and Tilley, J. (2002), “Packaging children’s breakfast cereal’’, British Food Journal, Vol. 104 No. 9, pp. 766-777.

Hunter, B.T. (2002), “Marketing foods to kids: using fun to sell’”, Consumers' Research, March, pp. 16-19.

Institute of Medicine (2006), "Food marketing to children and youth. Threat or opportunity?" available at: www.nap.edu/catalog.php?record_id = 11514 (accessed October 11, 2012).

Interagency Working Group on Food Marketed to Children (2011), Preliminary proposed nutrition principles to guide industry self-regulatory efforts: request for comments, available at: www.ftc.gov/os/2011/04/110428foodmarketproposedguide.pdf (accessed October 11, 2012).

Ip, J., Mehta, K.P. and Coveney, J. (2007), “Exploring parents’ perceptions of television advertising directed at children: a South Australian study’, Nutrition \& Dietetics, Vol. 64 No. 1, pp. 50-58.

Kelly, B., Chapman, K., Hardy, L., King, L. and Farrell, L. (2009), “Parental awareness and attitudes of food marketing to children: a community attitudes survey of parents in New South Wales”, Australia, Journal of Paediatrics and Child Health, Vol. 45 No. 9, pp. 1-5.

Kelly, J., Turner, J.J. and McKenna, K. (2006), “'What parents think: children and healthy eating’', British Food Journal, Vol. 108 No. 5, pp. 413-423.

Lapierre, M.A., Vaala, S.E. and Linebarger, D.L. (2011), “'Influence of licensed spokescharacters and health cues on children's rating of cereal taste', Archives of Pediatric and Adolescent Medicine, Vol. 165 No. 3, pp. 229-234.

Livingstone, S. and Helsper, E. (2004), “Advertising foods to children: understanding promotion in the context of children's daily lives”, available at: http://eprints.lse.ac.uk/21757/ (accessed December 10, 2012).

McDermott, L., O’Sullivan, T., Stead, M. and Hastings, G. (2006), “'International food advertising, pester power and its effects', International Journal of Advertising, Vol. 25 No. 4, pp. 513-540.

McNeal, J.U. and Ji, M.F. (2003), “Children’s visual memory of packaging”, Journal of Consumer Marketing, Vol. 20 No. 5, pp. 400-427, doi: 10.1108/07363760310489652. 
Marshall, D., Stuart, M. and Bell, R. (2006), "Examining the relationship between product package colour and product selection in preschoolers", Food Quality and Preference, Vol. 17, pp. 615-621, doi: 10.1016/j.foodqual.2006.05.007.

Mehta, K., Coveney, J., Ward, P. and Handsely, E. (2010), “Parents’ and children’s awareness and experience of food and beverage marketing on non-broadcast media", available at: http://sahealth.sa.gov.au/wps/wcm/connect/c134f780490e2a0fb1e3f57675638bd8/FU + Parent + and + child + awareness + Nonboardcast + media-PHCS-HPB-201010.pdf?MOD = AJPERES\&CACHEID = c134f780490e2a0fb1e3f57675638bd8 (accessed December 10, 2012).

Mehta, K., Phillips, C., Ward, P., Coveney, J., Handsley, E. and Carter, P. (2012), “'Marketing foods to children through product packaging: prolific, unhealthy and misleading”, Public Health Nutrition, Vol. 15 No. 9, pp. 1763-1770, doi: 10.1071/S1368980012001231.

Millar, S. (2005), “'Obesity: can packaging help?’, Paper, Film and Foil Converter, Vol. 79 No. 8, p. 24.

Musher-Eizenman, D.R., Oehlhof, M.W., Young, K.M., Hauser, J.C., Galliger, C. and Sommer, A. (2011), "Emerald dragon bites vs veggie beans: fun food names increase children's consumption of novel healthy foods", Journal of Early Childhood Research, Vol. 9 No. 3, pp. 191-195, doi: 10.1177/1476718X10366729.

Nixon, B. (2004), “Advertising and marketing to children - everybody's business”, Young Consumers, Vol. 5 No. 3, pp. 19-25, doi: 10.1108/17473610410814201.

Page, R., Montgomery, K., Ponder, A. and Richard, A. (2008), “'Targeting children in the cereal aisle: promotional techniques and content features on ready-to-eat cereal product packaging”, American Journal of Health Education, Vol. 39 No. 5, pp. 272-282.

Pettersson, A. and Fjellstrom, C. (2006), " Responsible marketing to children and their families”, Young Consumers, Vol. 7 No. 4, pp. 13-18, doi: 10.1108/17473610610717928.

Pires, C. and Agante, L. (2011), "Encouraging children to eat more healthily: the influence of packaging”, Journal of Consumer Behaviour, Vol. 10 No. 3, pp. 161-168, doi: 10.1002/cb.362.

Pocock, M., Trivedi, D., Wills, W., Bunn, F. and Magnusson, J. (2010), “Parental perceptions regarding healthy behaviours for preventing overweight and obesity in young children: a systematic review of qualitative studies”, Obesity Reviews, Vol. 11 No. 5, pp. 338-353.

Roberts, M. (2005), “Parenting in an obesogenic environment”, Journal of Research for Consumers, No. 9.

Samson, N. (2005), “Marketing food and drink to children responsibly”, Young Consumers, Vol. 6 No. 4, pp. 13-18, doi: 10.1108/17473610510701250.

Schwartz, M.B. and Ustjanauskas, A. (2012), "Food marketing to youth: current threats and opportunities”, Childhood Obesity, Vol. 8 No. 2, pp. 85-88, doi: chi.2012.0082.schw. 
Scrinis, G. (2008), “'On the ideology of nutritionism”, Gastronomica, Vol. 8 No. 1, pp. 39-48, doi: 10.1525/gfc.2008.8.1.39.

Silayoi, P. and Speece, M. (2004), “Packaging and purchasing decisions: an exploratory study on the impact of involvement level and time pressure', British Food Journal, Vol. 106 No. 8, pp. 607-628, doi: 10.1108/00070700410553602.

Spungin, P. (2004), “Parent power, not pester power’, Advertising \& Marketing to Children, April-June, pp. 37-40.

Tarasuk, V. (2010), “Policy directions to promote healthy dietary patterns in Canada', Applied Physiology, Nutrition, and Metabolism, Vol. 35 No. 2, pp. 229-233.

Tucker, G. (2004), “The importance of food and drink propaganda', Young Consumers, Vol. 6 No. 1, pp. 8-13, doi: 10.1108/17473610510814462.

Turner, J.J., Kelly, J. and McKenna, K. (2006), “'Food for thought: parents’ perspectives of child influence’’, British Food Journal, Vol. 108 No. 3, pp. 181-191, doi:

10.1108/00070700610651007.

Wansink, B., Just, D.R. and Payne, C.R. (2012), “'Can branding improve school lunches?’', Archives of Pediatric and Adolescent Medicine, Vol. 166 No. 10, pp. 967-968, doi:

10.1001/archpediatrics.2012.999.

Wilson, G. and Wood, K. (2004), “The influence of children on parental purchases during supermarket shopping”, International Journal of Consumer Studies, Vol. 28 No. 4, pp. 329-336.

World Health Organization (2010), "Set of recommendations on the marketing of foods and non-alcoholic beverages to children'”, available at: http://whqlibdoc.who.int/publications/2010/ 9789241500210_eng.pdf (accessed October 11, 2012).

Worsley, A. and Scott, V. (2000), “Consumers' concerns about food and health in Australia and New Zealand”, Asia Pacific Journal of Clinical Nutrition, Vol. 9 No. 1, pp. 24-32.

\section{Further reading}

Campbell, K.J., Crawford, D.A. and Hesketh, K. (2006), “'Australian parents’ views on the 5-6year-old children's food choices’, Health Promotion International, Vol. 22 No. 1, pp. 11-18, doi: 10.1093/heapro/dal035.

Klaus, C.H. (1994), “The chameleon 'I', ', in Yancey, K.B. (Ed.), Voices on Voice: Perspectives, Definitions, Inquiry, National Council of Teachers of English, Urbana, IL, pp. 111129.

White House Task Force on Childhood Obesity (2010), “Solving the problem of childhood obesity within a generation: White House Task Force on Childhood Obesity report to the President', available at: www. 
letsmove.gov/sites/letsmove.gov/files/TaskForce_on_Childhood_Obesity_May2010_FullReport. pdf (accessed October 11, 2012).

\section{About the authors}

Rebecca C. Den Hoed is a PhD Candidate in Communication Studies at the University of Calgary. Her research focuses on food voice and food politics. Rebecca C. Den Hoed is the corresponding author and can be contacted at: rcarruth@ucalgary.ca

Charlene Elliott holds a Canadian Institutes of Health Research (CIHR) Canada Research Chair in Food Marketing, Policy, and Children's Health at the University of Calgary. Her program of research focuses on the marketing of foods to children, food legislation and the politics of consumption. 